\title{
Sponge exhalent seawater contains a unique chemical profile of dissolved organic matter
}

\author{
Cara L Fiore ${ }^{\text {Corresp.. }}{ }^{1}$, Christopher J Freeman ${ }^{2}$, Elizabeth B Kujawinski ${ }^{1}$ \\ ${ }^{1}$ Marine Chemistry \& Geochemistry, Woods Hole Oceanographic Institution, Woods Hole, MA, United States \\ 2 Smithsonian Marine Station, Smithsonian Institution, Fort Pierce, FL, United States \\ Corresponding Author: Cara L Fiore \\ Email address: fiorec@appstate.edu
}

Sponges are efficient filter feeders, removing significant portions of particulate and dissolved organic matter (POM, DOM) from the water column. While the assimilation and respiration of POM and DOM by sponges and their abundant microbial symbiont communities have received much attention, there is virtually no information on the impact of sponge holobiont metabolism on the composition of DOM at a molecular-level. We applied untargeted and targeted metabolomics techniques to characterize DOM in seawater samples prior to entering the sponge (inhalant reef water), in samples exiting the sponge (exhalent seawater), and in samples collected just outside the reef area (off reef seawater). Samples were collected from two sponge species, Ircinia campana and Spheciospongia vesparium, on a near-shore hard bottom reef in the Florida Keys. Metabolic profiles generated from untargeted metabolomics analysis indicated that many more compounds were enhanced in the exhalent samples than in the inhalant samples. Targeted metabolomics analysis revealed differences in diversity and concentration of metabolites between exhalent and off reef seawater. For example, most of the nucleosides were enriched in the exhalent seawater, while the aromatic amino acids, caffeine and the nucleoside xanthosine were elevated in the off reef water samples. Although the metabolic profile of the exhalent seawater was unique, the impact of sponge metabolism on the overall reef DOM profile was spatially limited in our study. There were also no significant differences in the metabolic profiles of exhalent water between the two sponge species, potentially indicating that there is a characteristic DOM profile in the exhalent seawater of Caribbean sponges. Additional work is needed to determine whether the impact of sponge DOM is greater in habitats with higher sponge cover and diversity. This work provides the first insight into the molecular-level impact of sponge holobiont metabolism on reef DOM and establishes a foundation for future experimental studies addressing the influence of sponge-derived DOM on chemical and ecological processes in coral reef ecosystems. 
1 Sponge exhalent seawater contains a unique chemical profile of dissolved organic matter 2

3 Cara L. Fiore ${ }^{1, *}$, Christopher J. Freeman ${ }^{2}$, Elizabeth B. Kujawinski ${ }^{1}$

4

$5{ }^{1}$ Marine Chemistry and Geochemistry, Woods Hole Oceanographic Institution, Woods Hole, 6 MA 02543, U.S.A.

$7 \quad 2$ Smithsonian Marine Station, Fort Pierce, FL 34949, U.S.A

$8{ }^{*}$ Current address: Biology Department, Appalachian State University, Boone, NC 28607, U.S.A.

9 Corresponding author:

10 Cara Fiore

11 Appalachian State University

12572 Rivers St

13 Rankin Science Building

14 Boone, NC 28607 U.S.A.

15 fiorec@appstate.edu

16

17

18

19

20

21

22

23

24

25

26

27

28

29

30 


\section{Abstract}

33 Sponges are efficient filter feeders, removing significant portions of particulate and dissolved

34 organic matter (POM, DOM) from the water column. While the assimilation and respiration of

35 POM and DOM by sponges and their abundant microbial symbiont communities have received

36 much attention, there is virtually no information on the impact of sponge holobiont metabolism

37 on the composition of DOM at a molecular-level. We applied untargeted and targeted

38 metabolomics techniques to characterize DOM in seawater samples prior to entering the sponge

39 (inhalant reef water), in samples exiting the sponge (exhalent seawater), and in samples collected

40 just outside the reef area (off reef seawater). Samples were collected from two sponge species,

41 Ircinia campana and Spheciospongia vesparium, on a near-shore hard bottom reef in the Florida

42 Keys. Metabolic profiles generated from untargeted metabolomics analysis indicated that many

43 more compounds were enhanced in the exhalent samples than in the inhalant samples. Targeted

44 metabolomics analysis revealed differences in diversity and concentration of metabolites

45 between exhalent and off reef seawater. For example, most of the nucleosides were enriched in

46 the exhalent seawater, while the aromatic amino acids, caffeine and the nucleoside xanthosine

47 were elevated in the off reef water samples. Although the metabolic profile of the exhalent

48 seawater was unique, the impact of sponge metabolism on the overall reef DOM profile was

49 spatially limited in our study. There were also no significant differences in the metabolic profiles

50 of exhalent water between the two sponge species, potentially indicating that there is a

51 characteristic DOM profile in the exhalent seawater of Caribbean sponges. Additional work is

52 needed to determine whether the impact of sponge DOM is greater in habitats with higher

53 sponge cover and diversity. This work provides the first insight into the molecular-level impact

54 of sponge holobiont metabolism on reef DOM and establishes a foundation for future 
55 experimental studies addressing the influence of sponge-derived DOM on chemical and

56 ecological processes in coral reef ecosystems.

Introduction

Coral reefs exist in relatively oligotrophic environments where there is tight coupling between benthic and pelagic nutrient cycles (Wild et al., 2008; Naumann et al., 2012). As both filter feeders and hosts to abundant symbiont communities, sponges can have a major role in coral reef biogeochemistry (Southwell et al., 2008) through the removal of particles (Ribes et al., 2005 ) and the transfer of dissolved organic matter (DOM) to higher trophic levels in the benthos (de Goeij et al., 2013; Rix et al., 2016). Sponge holobiont (sponge plus associated microbes) metabolism has been shown to influence the composition of inorganic nitrogen (e.g., Southwell et al., 2008) and the concentration of dissolved organic carbon (DOC; Ribes, Coma, \& Gili,

67 1999; Yahel et al., 2003). However, the impact on the composition of DOM is not well characterized. DOM comprises dissolved organic carbon, nitrogen, phosphorus, and other elements (Hedges, 2002), but the carbon component is the largest. Recent studies have begun to examine the sources and major components of DOM on coral reefs. For example, macroalgae generally produce exudates that are higher in neutral sugars and in DOC concentration than coral exudates (Haas et al., 2011; Nelson et al., 2013). Studies comparing DOC from different sources and their effects on ecosystem function have begun to elucidate ecologically important connections between DOC, microbial community composition, and coral reef biogeochemical cycling (e.g., Wild et al., 2008; Haas et al., 2013). 
78 Nelson et al., 2013). DOM composition also influences coral health (Morrow et al., 2012) and

79 ecosystem-wide nutrient cycling (Wild et al., 2004). Corals, as well as algae, contribute to DOM

80 by releasing neutral sugars such as fucose and galactose, although the proportion of these

81 components is different between the two sources (Nelson et al., 2013). To date, however, our

82 understanding of the composition of coral reef DOM has been limited by methods that cannot

83 fully resolve the complex nature of DOM, particularly within the low-molecular weight

84 component (LMW DOM, < $1000 \mathrm{Da})$. This fraction could be particularly important to reef

85 ecosystems as it contains molecules that are produced during metabolism and that may be labile

86 to other organisms (e.g., Mazur \& Homme, 1993; Amin et al., 2015).

87 Sponges are typically considered to be a sink for DOM, releasing exhalent water that has

88 lower concentrations of carbon relative to water entering the sponge (Wilkinson 1987; Yahel et

89 al., 2003; de Goeij et al., 2008b; McMurray et al., 2016). It is thus not surprising that DOM is an

90 important carbon source for many sponges, contributing up to $10 \%$ of total carbon assimilated by

91 two deep water sponges (van Duyl et al., 2008) and contributing over an order of magnitude

92 more carbon to the biomass of coral reef sponges than POM (Yahel et al., 2003). The cryptic reef

93 framework, where sponges are common, has also been shown to be a major sink for DOM (van

94 Duyl \& Gast, 2001; de Goeij \& van Duyl, 2007), most of which is likely assimilated by sponges

95 (de Goeij et al., 2008b). Additionally, coral-excavating sponges rely largely on DOM to meet

96 their carbon demand and may be able to take advantage of nutrient-rich environments (Mueller et

97 al., 2014), highlighting the pivotal role of DOM in these ecosystems.

98 While the removal of DOM by sponges has been documented for some time (Stephens \&

99 Schinske, 1961; Reiswig, 1990; Alber \& Valiela, 1995; Ribes, Coma \& Gili, 1999), it was

100 unclear until recently whether sponge cells could assimilate DOM directly or only via their 
101 microbial symbionts (sensu De Bary, 1879). An experiment with isotopically labeled DOM and

102 particulate organic matter (POM) demonstrated that both sponge-associated microbes and the

103 sponge itself are capable of assimilating dissolved material (de Goeij et al., 2008a; de Goeij et al.,

104 2013), although the specific components of DOM removed by the sponge holobiont could not be

105 determined. A few studies have provided preliminary insight into these components, where the

106 uptake of several amino acids, but only a minimal amount of glucose, by sponges was observed

107 (Stephens \& Schinske, 1961; de Goeij et al., 2008a). The difference in uptake between the amino

108 acids and glucose may indicate some discrimination in the removal of metabolites from seawater

109 by the sponge holobiont, consistent with previous observations of differential metabolite removal

110 by marine free-living microbes (Malmstrom et al., 2004; Nelson \& Craig, 2012).

111 Sponges, with their high abundance on many reefs, particularly in the Caribbean (McMurray,

112 Finelli \& Pawlik, 2015), their large filtration capacity (upwards of $30 \mathrm{~L}^{-1} \mathrm{hr}^{-1}$ per L of sponge;

113 Weisz et al., 2008) and microbial symbiont diversity (e.g., Easson \& Thacker, 2014), likely

114 influence the composition and availability of DOM on coral reefs. Here we use high resolution

115 untargeted and targeted metabolomics techniques to probe the composition of DOM on a near

116 shore reef in the Florida Keys (U.S.A.) and to characterize the influence of the sponge holobiont

117 metabolism on DOM composition. Untargeted, or discovery-based, analysis allows for a semi-

118 quantitative profile-view of low molecular weight molecules within a sample, while the targeted

119 metabolomics approach provides a quantitative comparison of molecules relevant to the growth

120 of many organisms (Patti, Yanes \& Siuzdak, 2012; Kido Soule et al., 2015). In the present study,

121 two sponge species were selected for analysis that are known to harbor distinct symbiont

122 communities: Ircinia campana, a high microbial abundance (HMA) sponge and Spheciospongia

123 vesparium, a low microbial abundance (LMA) sponge (Poppell et al., 2014). By applying 
124 metabolomics analysis to inhalant and exhalent water of these two sponge species and to water

125 collected away from the reef, we demonstrate a complex dynamic of removal and addition of

126 labile DOM to the surrounding seawater that would be difficult to predict based solely on bulk

127 carbon analyses.

128

129 Materials and Methods

130 Sample Collection

131 Seawater samples were collected near Long Key State Park, FL (24.8169

$\left.132 \mathrm{~N} 80.8200^{\circ} \mathrm{W}\right)$ by scuba divers (4-5 $\mathrm{m}$ depth; Figure 1). Abundance data on sponge populations

133 were not obtained, but in general sponges were in relatively low abundance compared to

134 populations typical of offshore coral reefs in the Florida Keys. Acid-washed polypropylene

135 syringes (100 ml) attached to $1 \mathrm{~L}$ FlexFoil Plus sample bags (SKC, Pittsburgh, PA, USA) via a

136 three-way valve with Teflon tubing were used to collect ambient reef water and exhalent water

137 from the sponge. The valve allowed the syringe to be filled and then pumped into the bag ten

138 times to collect $1 \mathrm{~L}$ of seawater. Ambient reef water (herein referred to as inhalant) was collected

139 near each sponge but away from the direction of the exhalent plume. Exhalent water from each

140 sponge was collected by drawing water into the syringe slowly $\left(1 \mathrm{ml} \mathrm{s}^{-1}\right)$ through tubing placed

141 just above the osculum for Spheciospongia vesparium and just above the base of the spongeocoel

142 for Ircinia campana. All sponges (3 individuals per species) were checked for pumping activity

143 using fluorescein dye and sampled once the dye had visibly disappeared. The time the dye front

144 took to move from the base of the spongeocoel to the osculum was recorded in order to obtain

145 the centerline fluid velocity and to estimate pumping rates. While this method can be

146 confounded by sponge morphology (McMurray, Pawlik \& Finelli, 2014), it has been shown to 
147 provide a rough estimate of pumping rate at least within species (Weisz, Lindquist \& Martens,

148 2008; Southwell et al., 2008; Fiore, Baker \& Lesser, 2013). Thus, we used pumping rates to

149 provide an order of magnitude estimate for the release of metabolites to the reef. Volume

150 measurements described previously (McMurray, Blum \& Pawlik, 2008) were recorded for each

151 sponge using measuring tape (to $\pm 1.0 \mathrm{~mm}$ ) to calculate sponge volumes (McMurray, Blum \&

152 Pawlik, 2008; Weisz, Lindquist \& Martens, 2008). The height of the sponge was assumed to be

153 the height of the spongeocoel for $S$. vesparium. Off reef samples were collected in

154 polycarbonate bottles $(\mathrm{n}=2,1.5 \mathrm{~L}$ total $)$ by hand near the surface and approximately $300 \mathrm{~m}$

155 seaward from the reef, over a mix of sand and hard substrate.

156 The seawater was put on ice immediately upon end of the dive. Upon return to the

157 Smithsonian Marine Station (Fort Pierce, FL), subsamples (40 ml) of each water sample were

158 added to combusted vials and acidified to $\mathrm{pH}=2$ using $12 \mathrm{~N}$ hydrochloric acid, and stored frozen

159 for total organic carbon (TOC) analysis. TOC concentrations were used to calculate the

160 extraction efficiency for a subset of samples. The rest of the seawater was filtered through a

161 combusted glass fiber filter (GF/F; $0.7 \mu \mathrm{m}$, Whatman) and a $0.2 \mu \mathrm{m}$ PTFE filter (Omnipore,

162 Millipore, MA, UA). The filtrate was frozen and shipped to Woods Hole Oceanographic

163 Institution (WHOI, Woods Hole, MA) for extraction of dissolved organic matter.

164

165 Extraction of low molecular weight dissolved organic matter and instrument methods

166

167 Extractions of filtrate samples and the instrument methods used here were performed as

168 described in Kido Soule et al. (2015) and Fiore et al. (2015). Briefly, the seawater filtrate was

169 acidified to pH 3 (Longnecker, 2015) and then de-salted and extracted with1g/ 6 cc PPL solid 
170 phase extraction cartridges (BondElut, Agilent, Santa Clara, CA, USA) as described previously.

171 DOM was eluted from the column using $100 \%$ methanol prior to storage at $-20^{\circ} \mathrm{C}$ until analysis.

172 Just prior to mass spectrometry analysis on the instruments described below, the methanol

173 extract was dried down and redissolved in $500 \mu 1$ of 95:5 water:acetonitrile. Deuterated biotin

174 was added to each sample as a high-performance liquid chromatography (HPLC) injection

175 standard (final concentration $0.05 \mu \mathrm{g} \mathrm{ml}^{-1}$ ). At this stage, 100 and $200 \mu \mathrm{l}$ of the extract was

176 removed for targeted and untargeted metabolomics analysis respectively. Equal amounts of each

177 experimental extract were combined to create a pooled sample.

178 Samples for TOC analysis, once reaching WHOI, were stored at $4^{\circ} \mathrm{C}$ until analysis with a

179 Shimadzu TOC-V $\mathrm{CSH}_{\mathrm{CH}}$ total organic carbon analyzer (Hansell \& Carlson, 2001). MilliQ water

180 blanks, standard curves using potassium hydrogen phthalate, and certified standard reference

181 material (the latter provided by Prof. D. Hansell, University of Miami) were used for instrument

182 calibration and were made fresh each day. Targeted metabolomics analysis was performed using

183 high-performance liquid chromatography (Thermo PAL autosampler and Accela pump) coupled

184 to a triple stage quadrupole mass spectrometer (TSQ Vantage, Thermo Fisher Scientific, MA,

185 USA) via a heated electrospray ionization (H-ESI) source operated in both positive and negative

186 ion modes. A set of standards, consisting of amino acids, vitamins, nucleosides, and other

187 metabolites (Kido Soule et al., 2015), was used in the targeted method to identify and quantify

188 these compounds in the experimental samples. Some metabolites have low recovery yields

189 following SPE (W.M. Johnson, M.C. Kido Soule and E.B. Kujawinski, submitted), thus a subset

190 of 23 standards that have high recovery rates with SPE were analyzed in the experimental

191 samples. Selected reaction monitoring (SRM) conditions were optimized for each standard. 
192 Untargeted analysis of extracted metabolites was performed using high-performance liquid

193 chromatography (Micro AS autosampler and Surveyor MS pump plus) coupled via ESI to a

194 hybrid linear ion trap-Fourier transform-ion cyclotron resonance (FT-ICR) mass spectrometer

195 (7T LTQ FT Ultra, Thermo Fisher Scientific). Electrospray ionization is a soft ionization

196 technique and, as such, minimizes molecular fragmentation in the source. Thus, each mass

197 feature likely represents an individual compound. The pooled sample was analyzed every seven

198 injections in both the targeted and untargeted metabolomics methods for quality control. More

199 details on instrument methods have been previously described (Kido Soule et al., 2015; Fiore et

200 al., 2015), with the exception that only positive ion mode for the untargeted metabolomics

201 method was analyzed in the current study.

202

203 Metabolomics data analysis

204

205 Untargeted metabolomics data were manually inspected in XCalibur (2.0) for issues with

206 injection, contamination, or ion suppression by comparing peak intensities of the injection

207 standard in each sample, and peak intensities of the pooled samples prior to performing analysis

208 in XCMS. Peak intensities did not change substantially over the time course of the analytical run

209 so it is unlikely that there was any systematic decrease in instrument response over time. Manual

210 inspection of chromatograms in XCalibur did reveal contamination by plastics (e.g.,

211 polyethylene glycol) in all samples, easily distinguished by regularly spaced mass features (44

$212 \mathrm{~m} / \mathrm{z}$ ). These mass features were present from 9.3 to 11.3 minutes; therefore, all features within

213 this time frame were removed (263 mass features; 8\%). The untargeted metabolomics data were

214 processed with XCMS 1.38.0 (Smith et al., 2006) and CAMERA 1.18.0 programs (Kuhl et al., 
215 2012) in R. The resulting peak table from XCMS and CAMERA was further quality-checked by

216 retaining only mass features that were present in at least two out of the three pooled samples and

217 removing features within $10 \mathrm{ppm}$ of fluorescein (as $[\mathrm{M}+\mathrm{H}]^{+} ; 4$ features). Typical mass errors are

218 1-2 ppm, making this a very conservative criterion for fluorescein. Mass features are defined

219 here as a unique combination of mass-to-charge $(\mathrm{m} / \mathrm{z})$ value and retention time. Peak areas of

220 mass features are proportional to metabolite concentration (e.g., Fiore et al., 2015) and thus were

221 normalized to the filtrate volume for analysis. Mass features of interest that had an associated

222 fragmentation spectrum were processed using the xcmsFragment function in XCMS (Benton et

223 al., 2008) and the spectra were queried against the METLIN metabolomics database (Smith et al.,

224 2005) and in the program MetFrag (Wolf et al., 2010) as described in Fiore et al. (2015). All

225 metabolomics data are available through the MetaboLights online database

226 (http://www.ebi.ac.uk/metabolights/) by accession number MTBLS281.

227 Statistical analyses were performed with R statistical software (v3.0.2; R Core Team). The 228 function metaMDS (vegan package; Oksanen, 2016) was used to perform non-metric

229 multidimensional scaling (nMDS) of volume-normalized untargeted data. The dimensionality

230 was assessed by Monte Carlo analysis using 20 iterations with real data and 20 iterations with

231 randomized data for each of several dimensions $(n=2-5)$. Mantel tests were performed to

232 determine the coefficient of determination $\left(r^{2}\right)$ between ordinal distance of the nMDS and the

233 Bray-Curtis dissimilarity for both axes and each axis separately. Analysis of similarity

234 (ANOSIM) was performed to test for significant differences in the diversity and abundance of

235 mass features between groups detected in the nMDS. A paired T-test was used to compare peak

236 areas between all inhalant $(n=6)$ and all exhalent $(n=6)$ seawater samples with log

237 transformation to meet test assumptions (peaks required to be in five out of six replicates, any of 
238 which could have a missing sample). A Welch's T-test was used to compare exhalent seawater

239 samples by species (log transformed; peaks required to be in all three replicates per species).

240 The generated p-values were adjusted for multiple comparisons using false discovery rate (FDR;

241 Benjamin \& Hochberg, 1995).

242 Targeted metabolomics analysis was performed using five-to-seven point manually-curated

243 external calibration curves for each standard $\left(0.5-500 \mathrm{ng} \mathrm{ml}^{-1}\right)$ to determine relative metabolite

244 concentrations (XCalibur 2.0). The concentrations were then exported to Microsoft Excel. A

245 paired T-test, followed by FDR p-value corrections, was also used to test for significant

246 differences in log-transformed metabolite concentrations between the exhalent and inhalant reef

247 seawater samples within each species ( $\mathrm{n}=3$ per species). Additionally, metabolite concentration

248 data for the two sponge species were pooled to test for differences in concentration between all

249 exhalent and all inhalant seawater samples ( $n=6$ inhalant and $n=6$ exhalent), using a paired T-

250 test (log transformed) and p-values were adjusted as described above. NMDS and ANOSIM

251 were also used, as described for the untargeted metabolomics dataset, to test the effect of sample

252 type (inhalant, exhalent, and off reef) on metabolite composition from the targeted metabolomics

253 dataset. Vectors, representing correlations ( $\mathrm{n}=1000$ permutations) between metabolite

254 concentrations and sample type (inhalant, exhalent, off reef), were added to the plot using the

255 function envfit, part of the Vegan package in R. The length of the vector corresponds to the 256 strength of the correlation with a longer vector indicating a stronger correlation.

257 The amount ( $\mathrm{pmol}$ ) of a given metabolite added to the reef seawater from a sponge over a

258 24-hour day was calculated by multiplying the difference in concentration of the metabolite in

259 the exhalent and inhalant seawater $\left(\mathrm{pmol} \mathrm{L}^{-1}\right)$ by the minimum and maximum range of the

260 volumetric flow rate of the sponges (average $\left.=0.3 \mathrm{~L} \mathrm{~s}^{-1} \pm 0.28\right)$ then multiplied by the conversion 
261 of seconds to 24 hours. We assume that the sponge continues to pump over a 24 -hour period.

262 While sponges do cease pumping, this is highly sporadic occurring anywhere from 2 to 21 days

263 and lasting from 10 min to multiple days, depending on the species (Reiswig, 1971; Vogel, 1974;

264 Pile et al., 1997; McMurray, Pawlik \& Finelli, 2014). Thus, in one 24-hour period it is likely

265 that these sponges would continue to filter and pump water.

266

267 Results

268

269

Metabolic profiles of ambient reef water, sponge exhalent water, and off reef water

270

271

Volume normalized pumping rates were $0.17 \mathrm{~L} \mathrm{~s}^{-1} \mathrm{~L}^{-1}$ sponge $( \pm 0.11)$ for $S$. vesparium, with

272

an average volume of $2.4 \mathrm{~L}( \pm 0.7)$, and $0.08 \mathrm{~L} \mathrm{~s}^{-1} \mathrm{~L}^{-1}$ sponge $( \pm 0.12)$ for $I$. campana, with an

273

average volume of 15.6 L $( \pm 15)$. Extraction efficiency for the SPE-extracted DOM was

274

calculated for several representative samples (IC-A-1, SV-A-2, SV-E-1, SV-E-2, Off reef 1, Off 275 reef 2) and ranged from 23 to $59 \%$.

276 Untargeted metabolomics analysis yielded a total of 2,973 mass features across samples.

277 There was a large overlap in features across all samples, with about half of the features shared 278 between the three sample types (58\%). The sponge exhalent water had the highest number of 279 unique mass features (334 features, 12\%), followed by off-reef water (195 features, $7 \%$ ) and 280 inhalant reef water (73 features, 3\%). The exhalent seawater and off reef seawater shared the 281 most features $(347,12 \%)$, while the exhalent and inhalant seawater samples shared the fewest 282 features $(42,2 \%)$. Analysis of similarity following nMDS visualization indicated a significant 
283 difference between the sample groups of inhalant and off reef water combined relative to

284 exhalent water (Figure 2; ANOSIM, $\mathrm{R}=0.398, \mathrm{p}=0.016$ ).

285 Of the 2,003 mass features present in at least five out of six replicates of sponge exhalent and 286 inhalant water, $243(12 \%)$ were significantly more abundant in the exhalent water (T-test, FDR

287 adjusted $\mathrm{p}<0.05)$. In contrast, 12 features $(<1 \%)$ were significantly more abundant in inhalant 288 seawater than in exhalent water (T-test, FDR adjusted $\mathrm{p}<0.05$ ).

289 Because the off reef samples $(n=2)$ could not be statistically compared to the other sample

290 types, a threshold of 20X the average peak area was delineated to determine whether a peak was

291 higher in a particular sample type and then used for comparative analyses (Table 1). A similar

292 number of differential mass features were yielded using a threshold of 20X difference in peak

293 area and statistical analysis (T-test, $\mathrm{p}<0.05,430$ features greater in the exhalent than inhalant

294 samples, 52 greater in the inhalant samples), to compare the inhalant and exhalent seawater

295 samples. Using this threshold, the off reef samples were first compared to all of the inhalant

296 water samples $(n=6)$. Many features $(n=106)$ were elevated in the inhalant seawater relative to

297 the off reef samples. Interestingly, within these features that are abundant in the ambient reef

298 water, nearly half $(n=42)$ were significantly higher in the exhalent than in the inhalant water ( $T$ -

299 test, FDR adjusted $\mathrm{p}<0.05)$. In contrast, only three features were significantly higher in the

300 inhalant seawater (T-test, FDR adjusted $\mathrm{p}<0.05$ ). There were also 71 mass features that were

301 lower in the inhalant seawater compared to the off reef samples. Of these features, 32 were

302 significantly different between the exhalent and inhalant seawater, all of which were higher in

303 the exhalent seawater samples. The off reef samples were then compared to the exhalent

304 samples, yielding many features that were more abundant in the exhalent seawater samples,

305 particularly from $S$. vesparium (Table 1). Mass features of interest (i.e., those that were more 
306 abundant in a certain sample type as described above) with associated fragmentation spectra

307 were used to query metabolomics databases. None of the mass features investigated here

308 revealed a significant match to any characterized metabolites.

309 The overwhelming majority of mass features $(n=2,243,85 \%)$ were detected in both exhalent

310 sample groups (I. campana exhalent seawater, IC-E and S. vesparium exhalent seawater, SV-E).

311 Of these shared features, T-tests revealed no significant differences $(p>0.05)$ between the two

312 species following p-value adjustment. When all features present in the exhalent seawater samples

313 in each species were compared ( $\mathrm{n}=2,623$ features), 121 features had p-values below 0.05 ;

314 however, none of these were significantly different between inhalant and exhalent waters

315 following p-value corrections. A number of features were unique to IC-E and SV-E (156 and 227,

316 respectively); however, some of these features were highly variable in their corresponding

317 samples, yielding high p-values in statistical comparisons.

319 Targeted metabolomics analysis

320

321 Sixteen (of 23 possible) metabolites were detected and quantified in these samples, including

322 several amino acids, B vitamins, and nucleosides (Figures 3, 4). Most of the 16 metabolites were

323 detected in all sample types; however, the nucleoside xanthosine was only detected in the off-

324 reef samples. Seven of the 16 metabolites were highest in the off reef samples, including some

325 amino acids and caffeine, but also the glycerol derivative, glycerol-3-phosphate (Figure 3).

326 Within the reef samples (inhalant and exhalent), the exhalent water contained higher

327 concentrations of metabolites than inhalant seawater for several metabolites including most of

328 the nucleosides and the amino acid tryptophan (Figure 4). Statistical comparison of metabolite 
329 concentrations in inhalant and exhalent samples yielded no significant differences after p-value

330 corrections ( $T$ test, $p>0.05$ for all). Sample types (inhalant, exhalent, off reef) were significantly

331 different from each other as detected by $\operatorname{ANOSIM}(\mathrm{R}=0.42, \mathrm{p}=0.004)$. The $\mathrm{nMDS}$

332 visualization and vector overlays showed significant correlations between off reef seawater

333 samples and aromatic amino acids, caffeine, and xanthosine, while most of the nucleosides and

334 riboflavin were significantly correlated with the exhalent seawater samples (Figure 5; Table S1;

335 all p-values $<0.05$ ). The inhalant samples, however, were not significantly correlated to any of

336 the metabolites including pantothenic acid in the broader nMDS analysis (Figure 5; Table S1; p

$337>0.05$ ). Over 24 hours, with constant sponge pumping, $\sim 2$ pmol to $\sim 1 \mathrm{nmol}$ of the metabolites

338 quantified in the targeted method would be released to the water column from each sponge.

339 However, four metabolites (4-hydroxybenzoic acid, glycerol-3-phosphate, 5'-

340 methylthioadenosine, and pantothenic acid) were likely removed by the sponge holobiont, as

341 they were depleted in concentration in the exhalent seawater relative to the surrounding seawater

342 (Table 2). One metabolite, the folate precursor, 4-aminobenzoic acid yielded no net addition or

343 removal to the surrounding seawater as the average concentration in the exhalent and inhalant

344 samples were approximately equal (Table 2).

345

346 Discussion

347

348 The present study supports three main conclusions regarding the alteration of DOM by the

349 sponge holobiont: 1) the profile of DOM in the exhalent water is unique from the surrounding

350 seawater and seawater further away from the reef; 2) the influence of sponge-derived DOM on

351 the DOM profile of surrounding seawater is localized close to the exhalent plume; and 3) the 
352 DOM profiles of two sponge species with distinct microbial communities are highly similar. The

353 latter conclusion may indicate a characteristic "sponge holobiont signal" for sponge-derived

354 DOM, and provides a testable hypothesis for future work.

355 Several lines of evidence support the distinction of sponge-derived DOM profiles from those

356 of surrounding seawater. The analysis of similarity based on the untargeted metabolic profile of

357 the seawater samples indicated that the exhalent water samples were significantly different from

358 both the inhalant seawater and off reef seawater DOM profiles. Because the majority of mass

359 features were common to all sample types, this suggests that differences in the concentration of

360 individual compounds are driving the observed statistical separation in samples. However, it is

361 likely to be a combination of diversity and concentration differences in each sample type that are

362 responsible for the statistical observations. For example, there are 340 unique features in the

363 exhalent samples, a small portion of the overall number of features, but these unique features

364 may have a role in driving differences between sample types. Similarly, pairwise comparisons

365 between the shared features of exhalent and inhalant seawater indicated that over 400

366 metabolites exhibited significantly different concentrations between these two water types. The

367 majority of these differential features were elevated in concentration in the exhalent water,

368 indicating significant contribution of metabolites to the seawater within the immediate vicinity of

369 the sponge. Similarly, many mass features were enriched in the exhalent samples relative to the

370 off reef seawater samples. However, the lack of separation of inhalant and off reef seawater

371 samples based on DOM composition implies that the impact of the distinct exhalent profile is

372 spatially limited as it may be rapidly utilized or diluted.

373 While there is not a strong impact of sponge-derived DOM on the overall reef DOM profile,

374 the distinct profile of DOM in the exhalent plume of the sponges may influence the metabolism, 
375 and potentially community structure of the nearby pelagic microbial community (Judd et al.,

376 2006; Landa et al., 2013). Given the connections between the microbial community composition

377 and activity, biogeochemical cycling, and coral health (e.g., Dinsdale et al., 2008; Kline et al.,

378 2006; Haas et al., 2011), it is possible that sponge-derived DOM could also impact the coral reef

379 community as a whole. This work provides another avenue for investigating the dynamics of

380 coral reef microbial communities and the interactive effects of microbial and benthic invertebrate

381 metabolism on overlying seawater chemistry.

382 Part of the impact of sponge-derived DOM on seawater chemistry was estimated based on

383 the quantified metabolites. Our calculations indicated that over a $24 \mathrm{hr}$ period, these sponges

384 would release between $\sim 2$ picomoles to about a nanomole or more of many of the metabolites

385 quantified using targeted metabolomics analysis. In some cases, the sponges were a net sink for

386 compounds, including 4-hydroxybenzoic acid and pantothenic acid, supporting the idea that

387 sponges are removing certain compounds and adding other compounds to the seawater as it

388 passes through the sponge. As a comparison, total dissolved free amino acids (DFAA) have been

389 quantified previously in Biscayne Bay FL (USA), where their concentrations ranged from $\sim 15$ to

$39050 \mathrm{nM}$ in the surface waters between 1.5 and $10 \mathrm{~m}$ from shore (Lee \& Bada, 1977). DFAA are

391 typically a small portion of the total dissolved amino acid pool (Lee \& Bada, 1977; Sommerville

392 \& Preston, 2001), but are likely to be labile to the nearby microbial community (Jørgensen,

393 1987; Middelboe, Borch \& Kirchman, 1995). We estimate that up to a nanomole each of

394 tryptophan and phenylalanine would be released from each sponge each day, potentially making

395 these sponges an important source of these two amino acids to the DFAA pool. These results

396 support a unique profile of DOM derived from sponge exhalent seawater, with some components 
397 reduced in concentration and other components added or elevated in concentration, relative to the

398 surrounding seawater.

399 The metabolic profiles of the exhalent seawater from the two sponge species were not

400 significantly different and the overwhelming majority of mass features were present in the

401 exhalent seawater from both species. Further work is to ascertain the degree to which DOM

402 derived from other sponge species might be similar to our observations. Nevertheless, the degree

403 of similarity of the exhalent seawater profiles between I. campana and S. vesparium was

404 surprising given that these species have been characterized as HMA and LMA species, with

405 different density and diversity of symbionts (Poppell et al., 2014). The dichotomy between

406 HMA and LMA sponges is not always straightforward (Gloeckner et al., 2014), but several

407 studies have documented functional differences relevant to biogeochemical cycling between the

408 two categories of sponges (Weisz et al., 2007; Freeman, Easson \& Baker, 2014). In the case of

409 the species used in this study, there is a fairly well characterized dichotomy between the diverse

410 and abundant community in I. campana (HMA) and the notably low density of microbes in $S$.

411 vesparium (LMA; Hardoim \& Costa, 2014; Poppell et al., 2014). While the exhalent seawater

412 DOM profiles exhibited high overall similarity, more unique mass features were present in the

413 exhalent seawater from S. vesparium than from I. campana. In addition, there was a higher

414 number of features that were more abundant in the exhalent seawater of $S$. vesparium than of $I$.

415 campana compared to the off reef samples. Further work is needed to ascertain the degree to

416 which the overall DOM profile of seawater exiting from sponges represents general metabolic

417 waste, either from the sponges or their microbial symbionts. Previous work with marine

418 eukaryotic phytoplankton observed differences in DOM exudate composition among

419 phylogenetic groups (Romero-Castillo et al., 2011; Becker et al., 2014), consistent with the 
420 hypothesis that DOM exudate profiles could differ among closely related organisms such as

421 sponge species as well as between different organism types. Future work should focus on

422 whether the mass features observed in this study, particularly those unique to a sponge species or

423 elevated in one of the two species, are the result of symbiont or host metabolism and whether

424 such features are ecologically significant.

425 Both the targeted and untargeted metabolomics analyses suggest that sponges are reducing

426 the concentrations of some DOM components and increasing the concentrations of others. This is

427 expected because while the sponge holobiont would remove some compounds from the water for

428 assimilation and/or energy, waste products from metabolism are also likely to be added to the

429 seawater by the sponge. Consequently, sponge metabolism and filtration could have a significant

430 impact on the pelagic microbial community and on the success of organisms that rely on DOM

431 as a carbon source directly or indirectly via microbial symbionts. For example, boring sponges

432 rely on dissolved organic carbon (DOC) to meet their energy demands (at least $80 \%$ of TOC they

433 remove is DOC; Mueller et al., 2014). The impact of sponge-derived DOC, or DOM in general,

434 on the metabolism of boring sponges has not yet been investigated. In fact, to our knowledge,

435 there are no studies that have examined the influence of sponge-derived DOM on the growth and 436 metabolism of any coral reef organism.

437 The ecological relevance of sponge-derived DOM in coral reef ecosystems would, in theory, 438 be proportional to the impact that sponge metabolism has on the composition of DOM in the 439 surrounding seawater. Of the 106 mass features that were higher in all of the inhalant seawater 440 samples than the off reef samples, many $(n=42)$ were also higher in the exhalent relative to

441 inhalant seawater. This suggests that the surrounding reef DOM profile may be partially derived

442 from sponge exhalent seawater. Similarly, of the 71 features that were lower in the inhalant 
443 compared to off reef samples, 32 were significantly elevated in the exhalent samples relative to

444 the inhalant samples, further distinguishing the inhalant and exhalent seawater samples from

445 each other. The impact of these sponge-derived metabolites on coral reef nutrient dynamics is

446 likely to be multifaceted, with individual compounds having different activity in the

447 environment. Further experiments are necessary to determine the full impact of sponge-derived

448 DOM on the reef DOM profile.

449 A portion of the local impact of sponge-derived DOM on seawater chemical composition,

450 however, could be elucidated in the targeted metabolomics analysis. The targeted metabolomics

451 dataset is a small subset of metabolites compared to the metabolic profile generated by the

452 untargeted metabolomics analysis. Thus, it is not surprising to see differences between the two

453 datasets. For example, the untargeted metabolomics analysis indicated a clear difference between

454 the inhalant and exhalent seawater samples, while none of the quantified metabolites were

455 significantly different in concentration between these two sample types. There was a general

456 trend towards higher concentrations of some quantified metabolites, including several amino

457 acids, nucleosides and the vitamin riboflavin $\left(\mathrm{B}_{2}\right)$ in the exhalent water relative to inhalant

458 seawater, suggesting that sponges could be a source of these compounds in the reef ecosystem.

459 Meanwhile, In comparison to the reef samples, the two off reef samples contained higher

460 concentrations of xanthosine, caffeine, and aromatic amino acids, indicating a non-sponge source

461 for these compounds or rapid consumption of these compounds by the reef sponge holobiont.

462 These preliminary data further support holobiont metabolism as a factor influencing reef DOM

463 composition and suggest that, to some extent, there are differences in the composition of reef

464 DOM relative to that of nearby off reef seawater. 
Differences in metabolite concentration and composition between the reef samples and the

466 off reef samples can be illustrated by caffeine (1,3,7-trimethylxanthine) and the purine

467 nucleoside xanthosine. Caffeine exhibited similar behavior to the amino acids with high

468 concentrations in the exhalent seawater relative to inhalant seawater, and particularly high

469 concentrations in the off reef water compared to both the inhalant and exhalent seawater.

470 Caffeine is a purine alkaloid found in plants and is considered a contaminant in freshwater and

471 marine systems (Weigel et al., 2001; Gardinali \& Zhao, 2002; Singh et al., 2010; del Rey,

472 Granek \& Sylvester, 2012), with the potential to negatively impact coral-algal symbiosis

473 (Pollack, Balazs \& Ogunseitan, 2009). Caffeine concentrations in the off reef samples were

474 approximately 12 times higher than in the reef seawater even though the sponges examined here

475 were a net source of caffeine. There is likely a non-sponge source for caffeine off reef given the

476 concentration differences between on reef and off reef samples. Meanwhile, the nucleoside

477 xanthosine was detected only in the off reef seawater samples, suggesting that either there is no

478 major source of xanthosine within the reef environment or that there is a high uptake of

479 xanthosine within the reef, resulting in a low standing concentration that may be below our

480 detection levels.

481 The nearly constant source of DOM from sponges and the differences in DOM composition

482 between the reef (inhalant and exhalent) and off reef samples may influence the planktonic

483 community structure in these two habitats. In a four-year study in Mo'orea, such differences

484 were observed in the composition and abundance of bacterioplankton community members

485 between water overlying coral reefs and seawater away from the reef (Nelson et al., 2011). The

486 presence of particular sponge species on the reef or overall sponge community composition

487 could also influence reef DOC composition and concentration and, ultimately planktonic 
488

489

490

491

492

493

494

495

496

497

498

499

500

501

502

503

504

505

506

507

508

509

510

community structure. For instance, the Caribbean sponge, Xestospongia muta was found to feed selectively on live plankton, yet DOC, which comprised most of the TOC (84\%) in the inhalant seawater, accounted for most of the sponge diet (70\%) and the sponge retained DOC at rates of approximately -9 to 46\%, exhibiting both release and uptake of DOC (McMurray et al., 2016). Although evidence exists that TOC/DOC concentrations are highly variable across sites within the Caribbean and across ocean basins (Nelson et al., 2011; Haas et al. 2016), no studies to date have investigated the potential link to sponge community structure. If there are inherent differences between locations in terms of carbon concentration and composition, future work characterizing the DOM profiles and the benthic communities of geographically disparate sites may help to link the flux of individual metabolites with specific members of these communities. The fact that none of the metabolites driving the differences between sample types could be identified using metabolomics databases highlights the gaps in our knowledge of the composition of coral reef DOM and thus in the flow of biologically relevant nutrients in this system. This is not surprising, given that metabolomics databases are still growing and are generally biased towards human-associated metabolites. Even recent human metabolomics studies, however, can only identify $<2 \%$ of mass features generated by untargeted metabolomics analysis (e.g., Bouslimani et al., 2015; Quinn et al., 2016).

Classic examples of the impact of sponge holobiont metabolism on seawater chemistry include the addition of inorganic nitrogen and removal of DOC. Previous studies addressing such phenomena have demonstrated the complex roles that sponges play in coral reef ecosystems. The results presented here build on our understanding of the impact of sponges on the composition of coral reef DOM by demonstrating that sponges remove certain components of low molecular weight DOM and add other components. These actions resulted in a distinct profile of DOM in 
511 the exhalent seawater, which may influence the metabolic activity of the nearby pelagic

512 microbial community, with potential implications for coral reef biogeochemical cycling. In areas

513 with a high density of sponges, such as many of the off shore reefs in the Caribbean, sponge-

514 derived DOM may have a greater impact on the overall profile of coral reef DOM. Additionally,

515 the similarity of DOM profiles from sponges with distinct prokaryotic communities provides

516 preliminary evidence for a common sponge signal in seawater DOM. While this present study

517 was limited in size, it is the first high-resolution assessment of the impacts of sponge filtration

518 and holobiont metabolism on coral reef DOM, an important reservoir of organic nutrients in this

519 ecosystem. Finally, this work establishes a foundation for future hypothesis-driven studies aimed

520 at better understanding the role of sponges in ecological and biogeochemical processes on coral

521 reefs.

522

523

524

525

526

527

528

529

530

531

532

533

534

535

536

537

538

539

540

541

542

543

544

545

\section{Acknowledgements}

The authors would like to thank Kenan Matterson and Cole Easson for assistance in the field, Michael Lesser for syringes used in sampling, Krista Longnecker for TOC analyses and Melissa Kido Soule for help with metabolomics analyses, and K. Longnecker, M. Kido Soule, and Winn Johnson for comments that improved an earlier version of this manuscript. The authors would also like to thank Krin Grande for artwork assistance. The manuscript was improved by constructive reviews from L. Aluwihare and C. Nelson. This represents contribution number XXXX at the Smithsonian Marine Station in Fort Pierce, Florida.

\section{References}

Alber M, Valiela I 1995. Organic aggregates in detrital food webs: incorporation by bay scallops Argopecten irradians. Marine Ecology Progess Series 121:117-124.

Amin SA, Hmelo LR, van Tol HM, Durham BP, Carlson LT, Heal KR, Morales RL, Berthiaume CT, Parker MS, Djunaedi B, Ingalls AE, Parsek MR, Moran MA, Armbrust EV 2015. Interaction and signalling between a cosmopolitan phytoplankton and associated bacteria. Nature 522:98-101.

Amon RMW, Benner R 1996. Bacterial utilization of different size classes of dissolved organic matter. Limnology and Oceanography 41:41-51. 
546

547

548

549

550

551

552

553

554

555

556

557

558

559

560

561

562

563

564

565

566

567

568

569

570

571

572

573

574

575

576

577

578

579

580

581

582

583

584

585

586

587

588

589

590

591

Anderson MJ, Willis TJ 2003. Canonical analysis of principle coordinates: a useful method of constrained ordination for ecology. Ecology 84:511-525.

Benjamin Y, Hochberg Y 1995. Controlling the false discovery rate: a practical and powerful approach to multiple testing. Journal of the Royal Statistical Society Series B 57:289-300.

Benton HP, Wong DM, Trauger SA, Siuzdak G 2008. XCMS ${ }^{2}$ : processing tandem mass spectrometry data for metabolite identification and structural characterization. Analytical Chemistry 80:6382-6389.

Bouslimani A, Porto C, Rath CM, Wang M, Guo Y, Gonzalez A, Berg-Lyon D, Ackerman G, Moeller Christensen GJ, Nakatsuji T, Zhang L, Borkowski AW, Meehan MJ, Dorrestein K, Gallo RL, Bandeira N, Knight R, Alexandrov T, Dorrestein PC. 2015. Molecular cartography of the human skin surface in 3D. Proceedings of the National Academy of Sciences E2120-E2129. DOI:10.1073/pnas.1424409112

de Bary A 1879. De la symbiose. Rev Int Sci 3:301-309.

de Goeij JM, van Duyl FC 2007. Coral cavities are sinks of dissolved organic carbon (DOC). Limnology and Oceanography 52:2608-2617.

de Goeij J, Moodley L, Houtekamer M, Carballeira NM, van Duyl F 2008a. ${ }^{13}$ C-enriched dissolved and particulate organic carbon in the bacteria- containing coral reef sponge Halisarca caerulea: Evidence for DOM feeding. Limnology and Oceangraphy 53:13761386.

de Goeij J, van den Berg H, van Oostveen M, Epping E, van Duyl F 2008b. Major bulk dissolved organic carbon (DOC) removal by encrusting coral reef cavity sponges. Marine Ecology Progress Series 357:139-151.

de Goeij JM, van Oevelen D, Vermeij MJA, Osinga R, Middelburg JJ, de Goeij AFPM, Admiraal W 2013. Surviving in a Marine Desert: The Sponge Loop Retains Resources Within Coral Reefs. Science 342:108-110.

del Rey ZR, Granek EF, Sylvester S 2012. Occurrence and concentration of caffeine in Oregon coastal waters. Marine Pollution Bulletin 64:1417-1424.

Dinsdale EA, Pantos O, Smriga S, Edwards RA, Angly F, Wegley L, Hatay M, Hall D, Brown E, Haybes M, Krause L, Sala E, Sandin SA, Vega Thurber R, Willis BL, Azam F, Knowlton N, Rohwer F 2008. Microbial ecology of four coral atolls in the Northern Line Islands. PLoS ONE 3:e1584.

Easson CG, Thacker RW 2014. Phylogenetic signal in the community structure of host-specific microbiomes of tropical marine sponges. Frontiers in Microbiology 5:532.

Fay MP, Proschan MA 2010. Wilcoxon-Mann-Whitney or t-test? On assumptions for hypothesis tests and multiple interpretations of decision rules. Journal of Survey Statistics 4:1-39.

Fiore CL, Baker DM, Lesser MP 2013. Nitrogen Biogeochemistry in the Caribbean Sponge, Xestospongia muta: A Source or Sink of Dissolved Inorganic Nitrogen? PLoS ONE 8:e72961.

Fiore CL, Longnecker K, Kido Soule MC, Kujawinski EB 2015. Release of ecologically relevant metabolites by the cyanobacterium Synechococcus elongatus CCMP 1631. Environmental Microbiology 17:3949-3963.

Freeman CJ, Easson CG, Baker DM 2014. Metabolic diversity and niche structure in sponges from the Miskito Cays, Honduras. PeerJ 2:e695.

Gloeckner V, Wehrl M, Moitinho-Silva L, Gernert C, Schup P, Pawlik JR, Lindquist NL, Erpenbeck D, Wörheide G, Hetschel U 2014. The HMA-LMA dichotomy revisted: an electron microscopical survey of 56 sponge species. Biological Bulletin 227:78-88. 
592

593

594

595

596

597

598

599

600

601

602

603

604

605

606

607

608

609

610

611

612

613

614

615

616

617

618

619

620

621

622

623

624

625

626

627

628

629

630

631

632

633

634

635

636

637

Haas AF, Naumann MS, Struck U, Mayr C, el-Zibdah M, Wild C 2010. Organic matter release by coral reef associated benthic algae in the Northern Red Sea. Journal of Experimental Marine Biology and Ecology 389:53-60.

Haas AF, Nelson CE, Wegley Kelly L, Carlson CA, Rohwer F, Leichter JJ, Wyatt A, Smith JE 2011. Effects of Coral Reef Benthic Primary Producers on Dissolved Organic Carbon and Microbial Activity. PLoS ONE 6:e27973.

Haas AF, Nelson CE, Rohwer F, Wegley Kelly L, Quistad SD, Carlson CA, Leichter JJ, Hatay M, Smith JE 2013. Influence of coral and algal exudates on microbially mediated reef metabolism. PeerJ 1:e108.

Haas AF, Fairoz MFM, Kelly LW, Nelson CE, Dinsdale EA, Edwards RA, Giles S, Hatay M, Hisakawa N, Knowles B, Lim YW, Maughan H, Pantos O, Roach TNF, Sanchez SE, Silveira CB, Sandin S, Smith JE, Rohwer F 2016. Global microbialization of coral reefs. Nature Microbiology 1:16042

Hansell DA, Carlson CA 2001. Biogeochemistry of total organic carbon and nitrogen in the Sargasso Sea: control by convective overturn. Deep Sea Research Part II: Topical Studies in Oceanography 48:1649-1667.

Hardoim C, Costa R 2014. Microbial Communities and Bioactive Compounds in Marine Sponges of the Family Irciniidae-A Review. Marine Drugs 12:5089-5122.

Hedges JI 2002. Why dissolved organics matter? In: Biogeochemistry of Marine Dissolved Organic Matter, Hansell DA and Carlson CA eds. Academic Press, San Diego, p 1-3.

Johnson WM, Kido Soule MC, and Kujawinski EB. The effect of background organic matter and salt on extraction efficiency and quantification of dissolved metabolites in targeted marine metabolomics. Submitted, Analytical Chemistry

Jorgensen NOG 1987. Free amino acids in lakes: concentrations and assimilation rates in relation to phytoplankton and bacterial production. Limnology and Oceanography 32:97-111.

Judd KE, Crump BC, Kling GW 2006. Variation in dissolved organic matter controls bacterial production and community composition. Ecology 87:2068-2079.

Kido Soule MC, Longnecker K, Johnson WM, Kujawinski EB 2015. Environmental Metabolomics: Analytical Strategies. Marine Chemistry 177:1-62.

Kline DI, Kuntz NM, Breitbart M, Knowlton N, Rohwer F 2006. Role of elevated organic carbon levels and microbial activity in coral mortality. Marine Ecology Progress Series 314:119125.

Kuhl C, Tautenhahn R, Böttcher C, Larson TR, Neumann S 2012. CAMERA: An Integrated Strategy for Compound Spectra Extraction and Annotation of Liquid Chromatography/Mass Spectrometry Data Sets. Analytical Chemistry 84:283-289.

Landa M, Cottrell MT, Kirchman DL, Blain S, Obernosterer I 2013. Changes in bacterial diversity in response to dissolved organic matter supply in a continuous culture experiment. Aquatic Microbial Ecology 69:157-168.

Lee C, Bada JL 1977. Dissolved amino acids in the equatorial Pacific, the Sargasso Sea and Biscayne Bay. Limnology and Oceanography 22:502-510.

Longnecker K 2015. Dissolved organic matter in newly formed sea ice and surface seawater. Geochmica Et Cosmochimica Acta 171:39-49.

Malmstrom RR, Kiene RP, Cotrell MT, Kirchman DL 2004. Contribution of SAR11 bacteria to the dissolved dimethylsulfoniopropionate and amino acid uptake in the North Atlantic ocean. Applied and Environmental Microbiology 70:4129-4135.

Mazur H, Homme E 1993. Presence of auxin indole-3-acetic acid in the northern Adriatic Sea: 
638

639

640

641

642

643

644

645

646

647

648

649

650

651

652

653

654

655

656

657

658

659

660

661

662

663

664

665

666

667

668

669

670

671

672

673

674

675

676

677

678

679

680

681

682

683

phytohormones and mucilage. Marine Ecology Progress Series 99:163-168.

McMurray SE, Blum JE, Pawlik JR 2008. Redwood of the reef: growth and age of the giant barrel sponge Xestospongia muta in the Florida Keys. Marine Biology 155:159-171.

McMurray SE, Finelli CM, Pawlik JR 2015. Journal of Experimental Marine Biology and Ecology. Journal of Experimental Marine Biology and Ecology 473:73-80.

McMurray SE, Pawlik JR, Finelli CM 2014. Trait-mediated ecosystem impacts: how morphology and size affect pumping rates of the Caribbean giant barrel sponge. Aquatic Biology 23:1-13.

McMurray SE, Johnson ZI, Hunt DE, Pawlik JR, Finelli CM 2016. Selective feeding by the giant barrel sponge enhances foraging efficiency. Limnology and Oceanography 61:1271-1286.

Middelboe M, Borch NH, Kirchman DL 1995. Bacterial utilization of dissolved free amino acids, dissolved combined amino acids and ammonium in the Delaware Bay estuary: effects of carbon and nitrogen limitation. Marine Ecology Progress Series 128:109-120.

Morrow KM, Ritson-Williams R, Ross C, Liles MR, Paul VJ 2012. Macroalgal extracts induce bacterial assemblage shifts and sublethal tissue stress in Caribbean corals. PLoS ONE 7:e44859.

Mueller B, de Goeij JM, Vermeij MJA, Mulders Y, van der Ent E, Ribes M, van Duyl FC 2014. Natural diet of coral-excavating sponges consists mainly of dissolved organic carbon (DOC). PLOS ONE 9:e90152.

Naumann MS, Haas AF, Jantzen C, Iglesias-Prieto R, Wild C 2012. Benthic-pelagic coupling in a Caribbean reef lagoon affected by hurricane "Dolly." In: Proceedings of the $12^{\text {th }}$ International Coral Reef Symposium, Cairns, Australia, 1-5.

Nelson CE, Alldredge AL, McCliment EA, Amaral-Zettler LA, Carlson CA 2011. Depleted dissolved organic carbon and distinct bacterial communities in the water column of a rapidflushing coral reef ecosystem. The ISME Journal 5:1374-1387.

Nelson CE, Craig CA 2012. Tracking differential incorporation of dissolved organic carbon types among diverse lineages of Sargasso Sea bacterioplankton. Environmental Microbiology 14:1500-1516.

Nelson CE, Goldberg SJ, Kelly LW, Haas AF, Smith JE, Rohwer F, Carlson CA 2013. Coral and macroalgal exudates vary in neutral sugar composition and differentially enrich reef bacterioplankton lineages. The ISME Journal 7:962-979.

Oksanen J 2016. Vegan: an introduction to ordination. URL https://cran.rproject.org/web/packages/vegan/vignettes/intro-vegan.pdf.

Patti GJ, Yanes O, Siuzdak G 2012. Innovation: Metabolomics: the apogee of the omics trilogy. Nature Reviews Molecular and Cell Biology 13:263-269.

Pile AJ, Patterson MR, Savarese M, Chernykh VI, Fialkov VA 1997. Trophic effects of sponge feeding within Lake Baikal\&apos;s littoral zone. 2. Sponge abundance, diet, feeding efficiency, and carbon flux. Limnology and Oceanography 42:178-184.

Pollack K, Balazs K, Ogunseitan O 2009. Proteomic assessment of caffeine effects on coral symbionts. Environmental Science and Technology 43:2085-2091.

Poppell E, Weisz J, Spicer L, Massaro A, Hill A, Hill M 2014. Sponge heterotrophic capacity and bacterial community structure in high- and low- microbial abundance sponges. Marine Ecology 35:414-424.

Quinn RA, Navas-Molina JA, Hyde ER, Song SJ, Vázquez-Baeza Y, Humphrey G, Gaffney J, Minich JJ, Melnik AV, Hershend J, DeReus J, Durant A, Dutton RJ, Khosroheidari M, Green C, da Silva R, Dorrestein PC, Knight R 2016. From sample to multi-omics 
684

685

686

687

688

689

690

691

692

693

694

695

696

697

698

699

700

701

702

703

704

705

706

707

708

709

710

711

712

713

714

715

716

717

718

719

720

721

722

723

724

725

726

727

728

729 conclusions in under 48 hours. mSystems 1:e00038-16. DOI:10.1128/mSystems.00038-16

Reiswig H 1971. In situ pumping activities of tropical Demospongiae. Marine Biology 9:38-50.

Reiswig HM 1990. In situ feeding in two shallow-water Hexactinellid sponges. In: New Perspectives in Sponge Biology, Rützler K ed. Washington, DC: Smithsonian Institution Press, 504-510.

Ribes M, Coma R, Gili JM 1999. Natural diet and grazing rate of the temperate sponge Dysidea avara (Demospongiae, Dendroceratida) throughout an annual cycle. Marine Ecology Progress Series 176:179-190.

Ribes M, Coma R, Atkinson MJ, Kinzie RA 2005. Sponges and ascidians control removal of particulate organic nitrogen form coral reef water. Limnology and Oceanography 50:14801489.

Rix L, de Goeij JM, Mueller CE, Struck U, Middelburg JJ, van Duyl FC, Al-Horani FA, Wild C, Naumann MS, van Oevelen D 2016. Coral mucus fuels the sponge loop in warm- and coldwater coral reef ecosystems. Scientific Reports 6:18715.

Romera-Castillo C, Sarmento H, Álvarez-Salgado XA, Gasol JM, Marrase C 2011. Net production and consumption of fluorescent colored dissolved organic matter by natural bacterial assemblages growing on marine phytoplankton exudates. Applied and Environmental Microbiology 77:7490-7498.

Smith CA, O'Maille G, Want EJ, Qin C, Trauger SA, Brandon TR, Custodio DE, Abagyan R, Siuzdak G 2005. METLIN a metabolite mass spectral database. Therapeutic Drug Monitoring 27: 747-751.

Smith CA, Want EJ, O'Maille G, Abagyan R, Siuzdak G 2006. XCMS: Processing Mass Spectrometry Data for Metabolite Profiling Using Nonlinear Peak Alignment, Matching, and Identification. Analytical Chemistry 78:779-787.

Southwell MW, Weisz JB, Martens CS, Lindquist N 2008. In situ fluxes of dissolved inorganic nitrogen from the sponge community on Conch Reef, Key Largo, Florida. Limnology and Oceanography 53:986-996.

Stephens GC, Schinske RA 1961. Uptake of amino acids by marine invertebrates. Limnology and Oceanography 6:175-181.

van Duyl FC, Gast GJ 2001. Linkage of small-scale spatial variations in DOC, inorganic nutrients and bacterioplankton growth with different coral reef water types. Aquatic Microbial Ecology 24:17-26.

van Duyl FC, Hegeman J, Hoogstraten A, Maier C 2008. Dissolved carbon fixation by spongemicrobe consortia of deep water coral mounds in the northeastern Atlantic Ocean. Marine Ecology Progress Series 358:137-150.

Vogel S 1974. Current-induced flow through the sponge, Halichondria. The Biological Bulletin 147:443-456.

Weisz JB, Hentschel U, Lindquist N, Martens CS 2007. Linking abundance and diversity of sponge-associated microbial communities to metabolic differences in host sponges. Marine Biology 152:475-483.

Weisz JB, Lindquist N, Martens CS 2008. Do associated microbial abundances impact marine demosponge pumping rates and tissue densities? Oecologia 155:367-376.

Wild C, Haas AF, Naumann MS, Mayr C, el-Zibdah M 2008. Comparative investigation of organic matter release by corals and benthic reef algae - implications for pelagic and benthic microbial metabolism. In: Ft. Lauderdale, FL, USA, 1319-1323.

Wild C, Huettel M, Klueter A, Kremb SG, Rasheed MYM, Jørgensen BB 2004. Coral mucus 
730 functions as an energy carrier and particle trap in the reef ecosystem. Nature 428:66-70.

731 Wolf S, Schmidt S, Müller-Hannemann M, Neumann S 2010. In silico fragmentation for

732

733 computer assisted identification of metabolite mass spectra. BMC Bioinformatics 11:148.

Yahel G, Sharp JH, Marie D, Häse C, Genin A 2003. In situ feeding and element removal in the symbiont-bearing sponge Theonella swinhoei: Bulk DOC is the major source for carbon.

735 Limnology and Oceangraphy 48:141-149.

736 Wilkinson CR 1987. Interocean differences in size and nutrition of coral reef sponge populations.

737

738

739

740

741

742

743

744

745

746

747 


\section{Table $\mathbf{1}$ (on next page)}

Mass features that differentiate different sample types (off reef, inhalant, exhalent) for each sponge species (Ircinia campana (IC) and Spheciospongia vesparium (SV)).

To determine whether a peak was higher in a particular sample type, a threshold of 20x (average peak area) was used for comparison because the off reef seawater samples have two replicates and thus could not be compared with conventional statistics. Numbers represent features that are greater in the row sample than in the column sample (for instance there were 164 mass features that were, on average, at least $20 x$ higher in the IC inhalant samples than in the off reef samples). 'n.d.' = not determined. 


\begin{tabular}{|l|c|c|c|c|c|}
\hline & Off reef & IC-Inhalant & SV-Inhalant & IC-Exhalent & SV-Exhalent \\
\hline Off reef & -- & 156 & 164 & 81 & 55 \\
\hline IC-Inhalant & 164 & -- & n.d. & 27 & n.d. \\
\hline SV-Inhalant & 155 & n.d. & -- & n.d. & 56 \\
\hline IC-Exhalent & 601 & 584 & n.d. & -- & 93 \\
\hline SV-Exhalent & 587 & n.d. & 608 & 26 & -- \\
\hline
\end{tabular}

1 


\section{Table 2 (on next page)}

Estimated release of metabolites from sponges based on targeted metabolomics analysis.

The average concentration of each metabolite in the inhalant and exhalent seawater with standard deviation is shown. The average concentration in the exhalent water and the minimum and maximum pumping rate (average $=0.3 \mathrm{~L}^{-s} \pm 0.28$ ) was used to estimate the amount of metabolite released per sponge over 24 hours. MTA = 5'-methylthioadenosine. 


Metabolite
Tryptophan
Kynurenine
Tryptamine
Phenylalanine
Tyrosine
4-hydroxybenzoic acid
4-aminobenzoic acid
Glycerol-3-phosphate
MTA
Adenosine
Guanosine
Inosine
Caffeine
Pantothenic acid
Riboflavin

\begin{tabular}{|c|c|}
\hline $\begin{array}{c}\text { Inhalant } \\
\left(\mathbf{f m o l ~ L ^ { - 1 } \pm S D}\right)\end{array}$ & $\begin{array}{c}\text { Exhalent } \\
\left(\text { fmol } \mathbf{L}^{-1} \pm \mathrm{SD}\right.\end{array}$ \\
\hline $18( \pm 9)$ & $50( \pm 30)$ \\
\hline $7( \pm 2)$ & $8( \pm 3)$ \\
\hline $15( \pm 3)$ & $18( \pm 5)$ \\
\hline $70( \pm 21)$ & $95( \pm 57)$ \\
\hline $4( \pm 4)$ & $12( \pm 12)$ \\
\hline $65( \pm 36)$ & $53( \pm 26)$ \\
\hline $2( \pm 0.5)$ & $2( \pm 0.6)$ \\
\hline $13( \pm 6)$ & $10( \pm 12)$ \\
\hline $7( \pm 2)$ & $4( \pm 0.8)$ \\
\hline $6( \pm 2)$ & $10( \pm 12)$ \\
\hline $3( \pm 2)$ & $19( \pm 25)$ \\
\hline $6( \pm 2)$ & $20( \pm 16)$ \\
\hline $8( \pm 3)$ & $17( \pm 20)$ \\
\hline $23( \pm 5)$ & $9( \pm 6)$ \\
\hline $2( \pm 1)$ & $3( \pm 2)$ \\
\hline
\end{tabular}

$\begin{array}{cc}55 & 1604 \\ 2 & 50 \\ 5 & 130 \\ 43 & 1253 \\ 14 & 400 \\ -21 & -601 \\ 0 & 0 \\ -5 & -150 \\ -5 & -150 \\ 7 & 200 \\ 28 & 802 \\ 24 & 702 \\ 16 & 451 \\ -24 & -702 \\ 2 & 50\end{array}$




\section{Figure 1}

Schematic of sampling location and sample types.

The three sample types are shown: inhalant, exhalent, and off reef seawater. The red vaselike sponges represent Ircinia campana and the gray sponges represent Spheciospongia vesparium. The numbers of samples collected for each sample type are shown. For inhalant and exhalent samples, one sample type was collected from each of three individuals. Reef seawater samples were collected near the surface approximately $300 \mathrm{~m}$ from the reef area. Arrows represent direction of water flow and color is associated with samples representing each sponge species in later figures.

\section{Sea Surface}

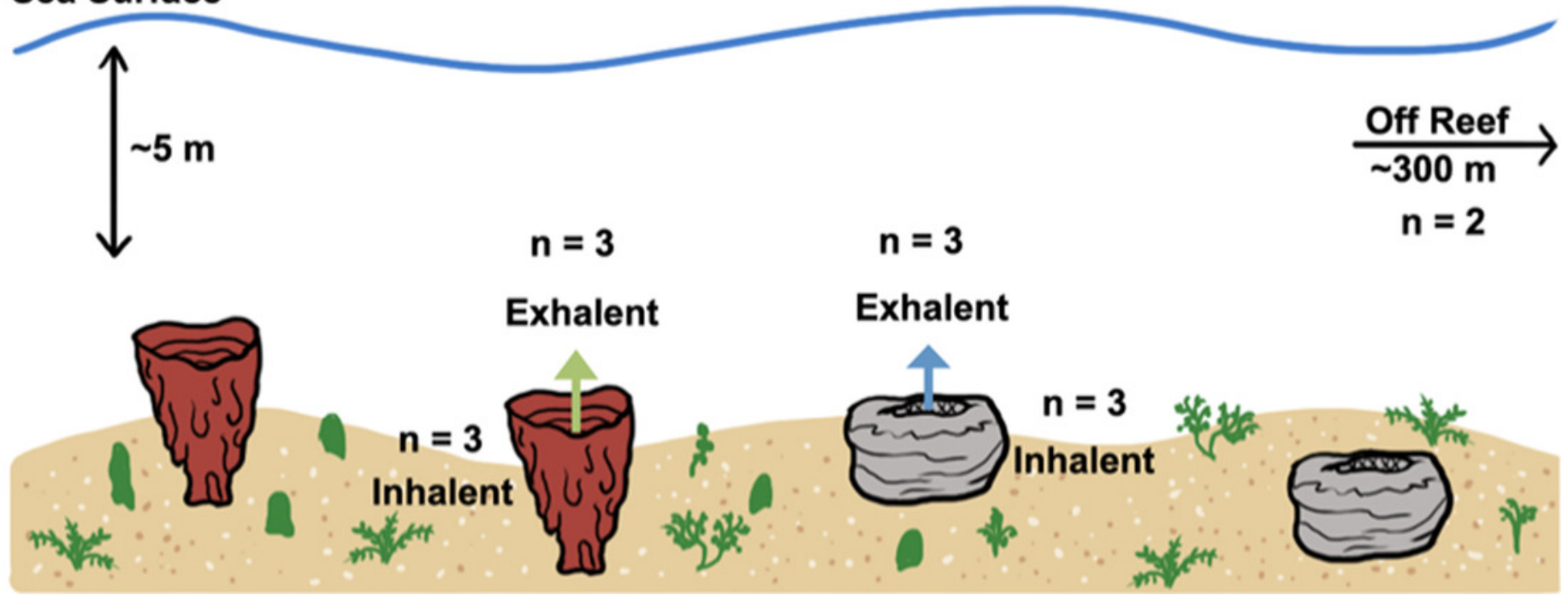




\section{Figure 2}

Non-metric multidimensional scaling (nMDS) plot of dissolved organic matter profiles from untargeted metabolomics analysis.

The strength of the correlation between the distance matrix and the nMDS plot distance are given for each axis and the overall plot. Samples are Ircinia campana (IC), Spheciospongia vesparium (SV), and off reef. Two groups were distinguished based on analysis of similarity (ANOSIM, $R=0.398, p=0.016$ ), which are highlighted by the black ovals. Off reef and inhalant (I) seawater samples grouped together on the left and the exhalent (E) seawater samples grouped together on the right.

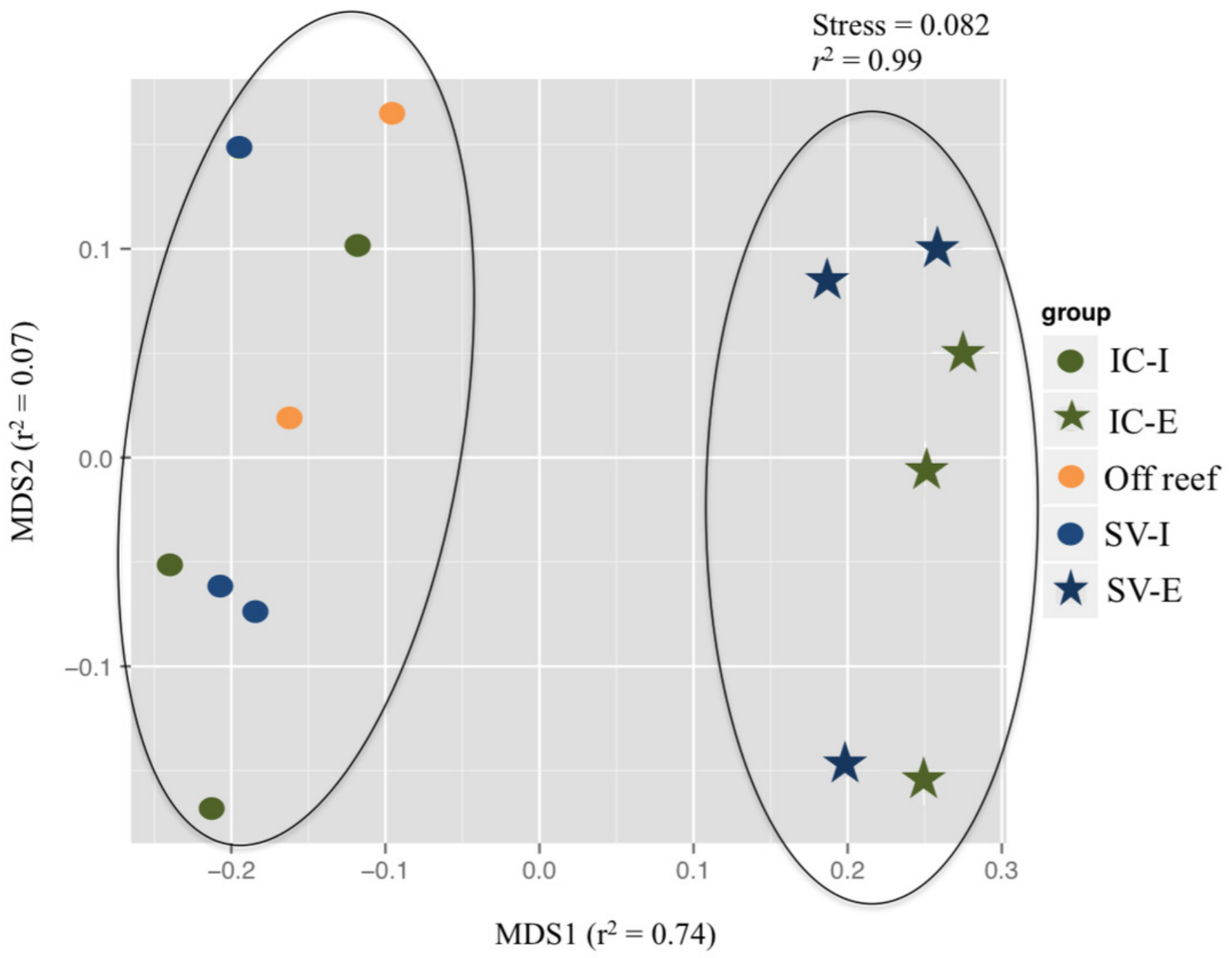


Figure 3

Average (+SD) ratios of metabolite concentrations of off reef and inhalant seawater samples (off reef/inhalant).

Note that the $y$-axis is presented as log2 scale to highlight equivalent concentrations (ratio = 1; red dashed line). The ratio of each metabolite was calculated by averaging individual ratios of each of the two off reef and each inhalant sample (12 ratios). MTA $=5$ 'methylthioadenosine. Xanthosine is not shown as it was only detected in the off reef samples.

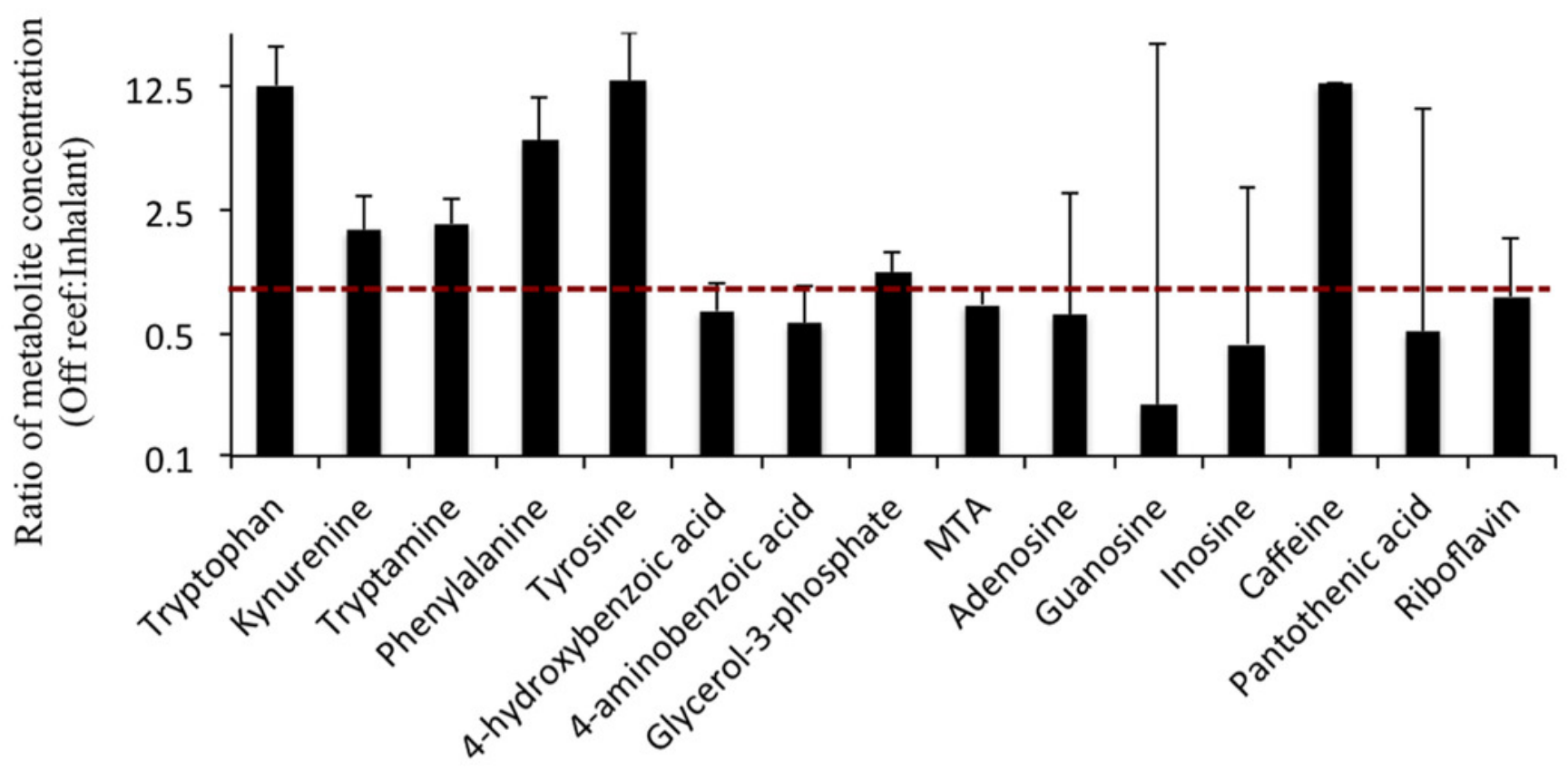


Figure 4

Average (+SD) ratio of metabolite concentration of exhalent and inhalant seawater samples (exhalent/inhalant) for each sponge species (IC = Ircinia campana; SV = Spheciospongia vesparium).

Note that the $y$-axis is presented as a $\log 2$ scale to highlight equivalent concentrations (ratio $=1$; red dashed line). No significant differences were observed between the concentrations of metabolites in the inhalant and exhalent seawater samples. Asterisks indicate metabolites that were detected in only one or two replicates of the inhalant samples resulting in no standard deviation for that metabolite ratio. MTA $=5^{\prime}$-methylthioadenosine. $n=3$.

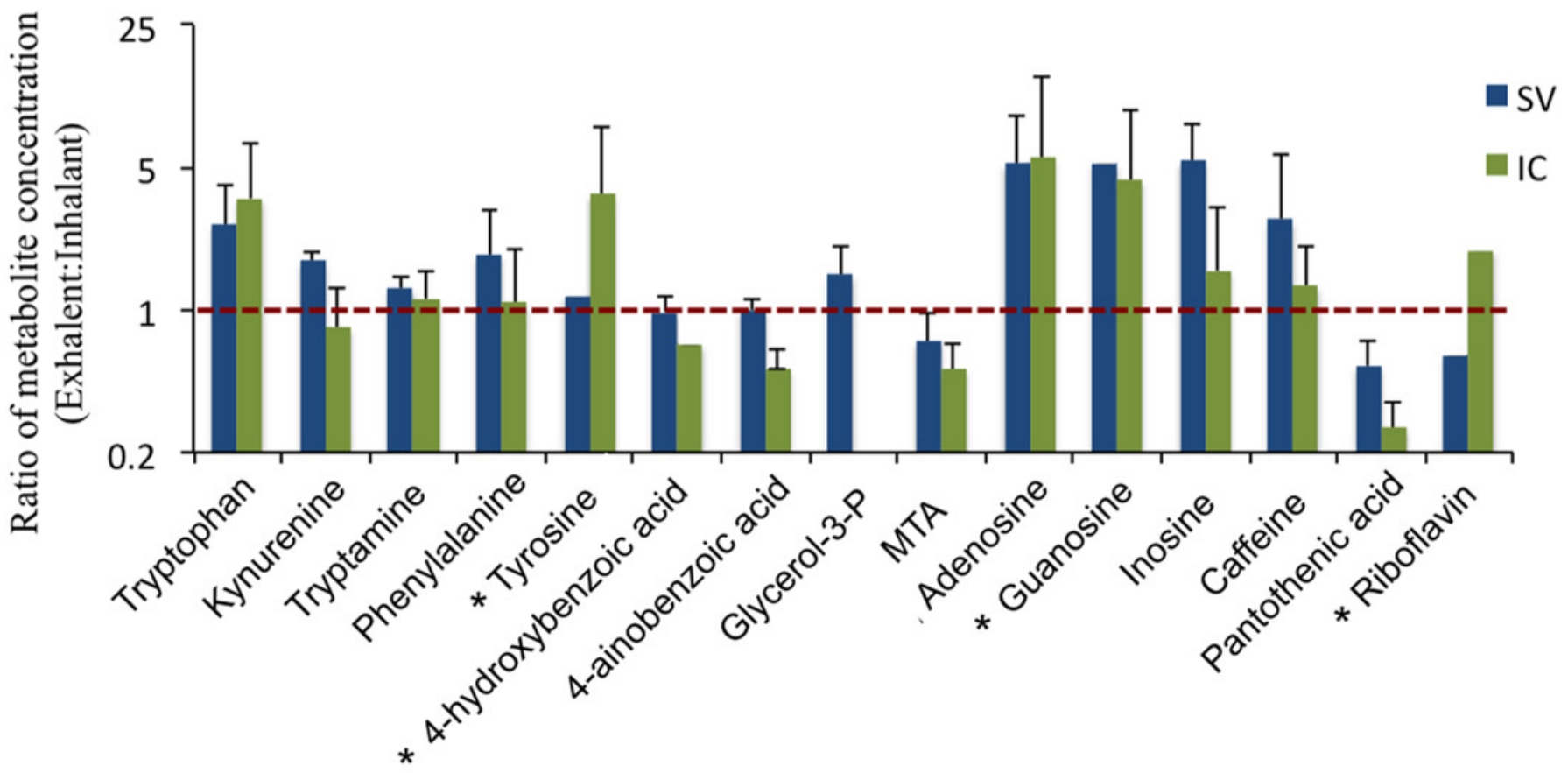




\section{Figure 5}

Non-metric multidimensional scaling (nMDS) plot of metabolite concentrations based on targeted metabolomics analysis.

The strength of the correlation between the distance matrix and the nMDS plot distance are given for each axis and the overall plot. Samples are exhalent (for both sponge species), inhalant (for both sponge species), and off reef. These three groups were distinguished based on analysis of similarity (ANOSIM, R $=0.42, p=0.004$ ). Vector overlays are based on correlations between metabolite concentration and sample type (inhalant, exhalent, off reef) with a longer vector indicating a stronger correlation. Correlations with pantothenic acid, MTA, and 4-aminobenzoic acid were not significant. G3P = glycerol-3-phosphate, MTA $=5$ 'methylthioadenosine.

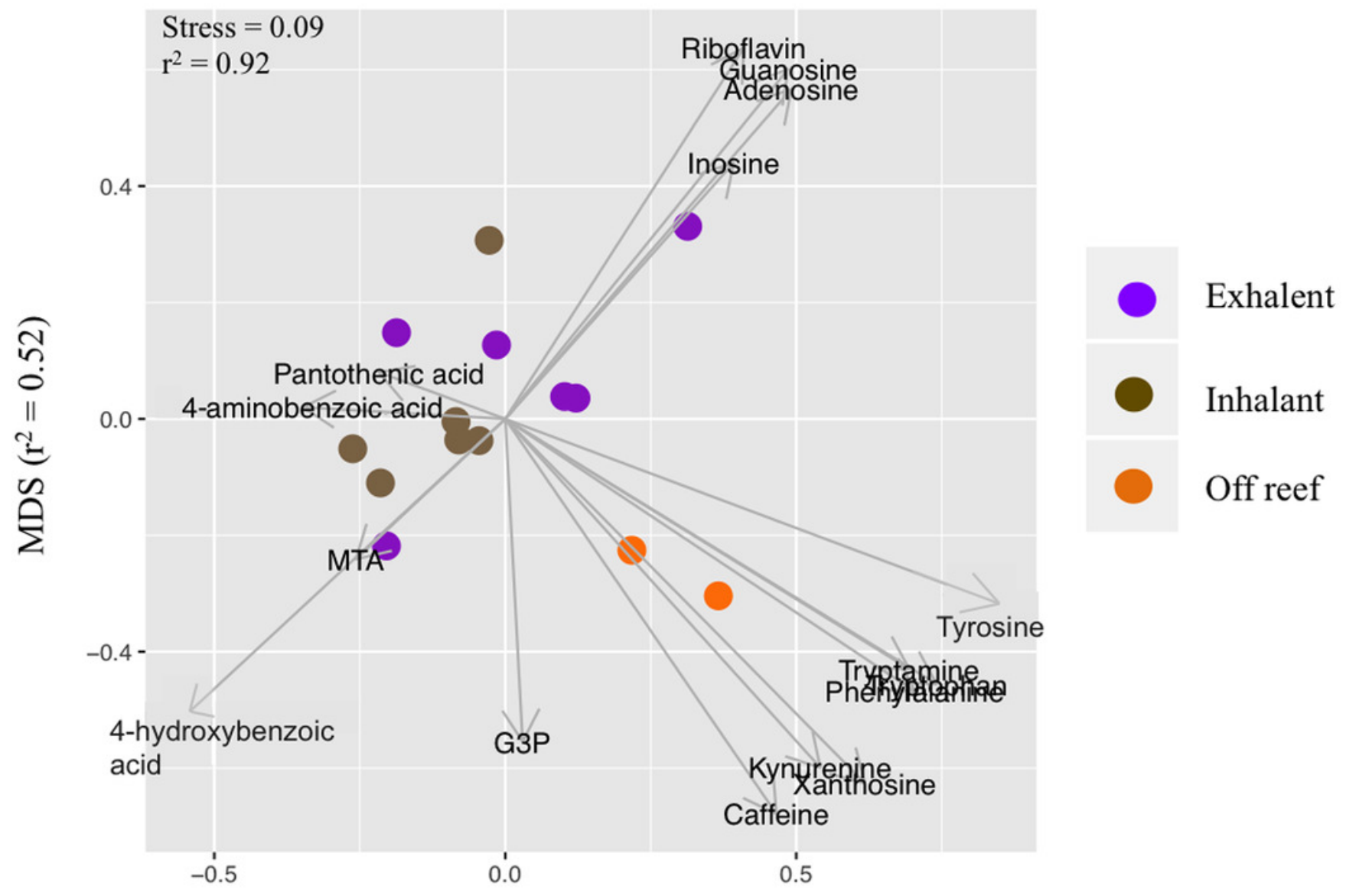

